\title{
Illumination and Color in Interior Design of Living Room
}

\author{
HalaBarakat Elnaggar \\ AssociateProfessor Department ofArchitecture,AASTMT, Sheraton, Cairo,Egypt
}

\begin{tabular}{l|l|l|l|} 
Submit Date:2021-05-14 22:06:15 & Revise Date:2021-10-07 09:42:05 & Accept Date:2021-10-06 15:31:25
\end{tabular}

DOI:10.21608/jdsaa.2021.76256.1112

\section{KEYWORDS:}

Person, process, product, creative, skill.

\begin{abstract}
:
The process of interior design is effectively linked with the function and aesthetics of the space. It is also the way of turning space from a mere expression of material and masses into living objects through which the space user lives the story of feeling for the art of interior design.

There are factors which affect the individual's peace and comfort; these include the psychological effects of light regulation, the features of the material, and the choice of colors (warm or cold). Because of the importance of illumination and colors and their vital effect in developing interior space and controlling the psychological and physiological comfort of the space user, this paper has been prepared to explore the role of utilizing light and colors in interior design of Living Rooms (in Cairo-Egypt) in order to support and develop the design process aiming to provide psychological, environmental and visual comfort inside the space.

The model aims to set criteria for providing illumination, both natural and artificial and also colors, together with setting bases for the interior design of different spaces within the living room. A descriptive analytical approach is implemented through a thorough study of colors and lighting and their effective relationship within the space of living room. Fifty prospective dwellers participated in a survey using virtual reality environments that presented required design bases for selected colors and lighting groups in living rooms. The aim was to measure the physiological and psychological effect of the selection of colors and lighting on man.
\end{abstract}

\section{1- Introduction:}

The designer visualizes a complete picture of the space, color scheme, effect of lighting on the space and main surfaces within the visual field of the space. The main aim of interior design is to develop the functionality, enrich the aesthetics, and consider the psychological effects of the interior space (Ertek, 1994).

The visual field is the point of view and evaluation of the interior space which has functional and aesthetical successful human nature. Light and color become softer on the eye either by reflection or refraction of light on colored surfaces to draw an environment that has different degrees of illumination. Light and colors interact within the space, each affects the other. So, the traditional approach of the function of light and the role of colors in interior architecture must be changed by reforming a design that relies on effect of light and not the light itself, besides the color psychology and not as color areas only. To achieve that, we have to present the main and important points which influence the design of interior space. 
Literature concerning studies combining illumination and color in interior design of living room are not readily available. There is some difficulty in locating enough studies around the effects of light and color in space. Importance of the results of this research arises from the fact that it fills the gap in literature concerning measuring the physiological and psychological effect of the selection of colors and lighting of living room on people.

Flynn is considered as the a pioneer in the field of studying interior lighting psychology, see (Flynn et al.,1973; Flynn,1977; Flynn \& Spencer,1977 and Flynn et al.,1979). He was the first to study lighting's impact on human cognition, mood, impression, and behavior. In his earliest studies of lighting psychology, Flynn found that lighting did have some effect on behavior, sensations and well-being of humans, (Flynn et al.,1973). More importantly, he found that lighting effects could be evaluated through psychological procedures (Flynn et al., 1973). Since the 1970s, many studies have been built on Flynn's research.

The arrangement and choices of natural and artificial lighting contribute to the desired mood and purpose of the space. This study provides new data about the effects of natural and artificial lighting on individuals in Living Room, as it is where one should feel most comfortable.

With these facts in mind, this study utilizes light and colors in interior Design of Living Room to support and develop the design process aiming to provide psychological, environmental and visual comfort for users of the space, and to determine if individuals had a preference to natural or artificial light in an interior living room space. This study used the same categories established in the study by (Durak et al.,2006) as they had already been determined to show useful, individual aspects of feelings towards a space.

(Durak et al.,2006) and (Flynn et al., 1973) studied the qualitative aspects of a space by different lighting arrangements such as general lighting, wall washing, and cove lighting. Subjects rated a room based on clarity, spaciousness, relaxation, privacy, pleasantness, and order.

The review of literature highlights several studies that relate specifically to the individual interior design element of light. Beginning with the first issue of the Journal of Interior Design, light has been identified as an area of study in education and practice, (Bartholomew, 1975).

According to an article in the Journal of Research Technology, exposure to artificial lighting has both positive and negative impacts on human health, (Boyce, 2006). Additionally, lighting has been researched with special consideration given to end-users preferences, (Gifford et al.,1993) post-occupancy evaluations. (Danfordet al.,1977) and impact upon human behavior. (Bartholomew, 1975; Heschong, 2002).

The interior design element of color impacts interior environments and their users in many different ways. The review of literature indicates that many studies have been conducted on color, with several different variables of color being researched. For example, a study published in the Journal of Interior Design reveals that color has behavioral connotations and can influence the user's mental and emotional balance, (Crowell et al.,1980). A second study researches the meaning of color in interior environments, (Guerin et al.,1995). A third one indicates that different colors impact memory, (Bynum et al.,2006).

Results of this study can be of use by interior architects, and designers who utilize color and light in order to create different atmosphere in a space. It is important to know the effects of light and color in a space for designers, as it is good to use color and light in a space knowing what kind of influence they may have on the space. Results may also concern the researchers who study color, and its effect on human psychology and perception.

\section{Architectural Definitions:}

1- Characteristics of colors, Psychological and Physiological Effects:

Studying colors and effect of colors on interior decoration is of vital importance. It is similar to how cheerful a person feels when it is sunny; and how unhappy a person feels on a rainy day. Color has the energy to influence both emotions and attention, (Kalia,2013; Engelbrecht , 2003;Zelanskiand Fisher,2003) and Shabha, 2006).

Colors used in interior design may have the ability to create certain moods, define unity and alter the perception of how large or small a space may fell or look. There are three basic colors, which are red, yellow and blue. Accent colors are formed by mixing two primary colors (the three secondary colors are green, orange and purple). Colors that are located opposite 
to each other on the color spectrum are called complementary colors. These colors are blue and orange, purple and yellow, green and red.

Another categorization is based on the effect that colors have on man, which is cold and warm. Warm colors are red, orange and yellow; while cold colors are blue, green and purple. (Artut, 2004).

Colors do have an impact on our emotions. Warm colors usually have the effect of liveliness, joy, excitement, and action. Cold colors lead more to calmness, comfort and relaxation (Altınçekiç, 1994), Table (1). Understanding psychological properties of different colors and their effect on spaces users helps considerably the interior designer. The impact of color together with form, appearance, texture and scale are all important factors in design. This impact may enormously influence human life. Knowing the psychological effects of colors is a must to people working in various areas of design (interior architecture).

\section{2- Color and Texture:}

Texture has the ability to add interest and detail to a surface, making it visually pleasing to the eye. In essence, it gives feeling to a room and adds specific characteristics to a surface which distinguishes it from other surfaces of the composition. Because every natural and artificial matter has its own texture, the property of color will be closely connected to texture. This means that using soft surfaces unlike using rough surfaces which can bear one color degree. Color and texture are inseparable twins. They create an expressive meaning that has an effect on the way a human might feel about the interior space, (Krstić, 2013).

Texture comes in two forms - visual texture and actual texture. Visual texture refers to a texture that is perceived by the eye. In other words, this is the impression of texture one gets by only viewing an object.

\section{3- Color and Light}

Changes in an object's color can also result from the effects of light. This factor is very important as it can change any environment with colors. Light effects on colors can drastically change the space. Day light can be warm or cool, depending on time of the day and the direction that light comes from. Warm light tends to emphasize warm colors and alters cool hues, while cool light intensifies cool colors and weakens warm hues. If light is tinted with a particular hue, it will raise the intensity of the colors of that particular hue and neutralize colors of a complementary hue. The value of color can also be altered by the amount of light used to illuminate the space. Lowering the amount of illumination will darken color's value and neutralize its hue.

High levels of illumination, however, can also intend to make colors appear less saturated or washed, (Sadat, 2011)

Man cannot see color without light and the surrounding forms first. Man moves through a space in real time, responding subjectively or physiologically to the color/light/form interrelationships as simultaneous (and not static) experiences. After our initial impressions, we continue to move and accept the environment as active, responding to the visual cues of color, material, light: each plays one against the other, (Varland, 1998).

\section{4- Patterns}

Paired with color, pattern offers a similar use to texture in that it can add appeal to a room. Patterns come in various types, such as stripes, geometric, pictorial, organic, motif and animal prints.

When implementing pattern, it's best to first consider the size and style of a room. Patterns that create vertical or horizontal lines can be used to give a heightened sense of space. Complex patterns made up of contrasting colors and lines can liven up a room, however they are best used in the form of a feature wall. Large scale patterns can flourish in a large space and become a distinct focal point to the room. (Duyan, 2016).

\section{Research Problem:}

There are some shortcomings due to the lack of accurate evaluation of link between color and light and bases of space design.

This paper is focusing on the effect of light (daylight and artificial ) and color in interior Design of Living Room to support and develop the design process to provide psychological, environmental and visual comfort inside the space of the living room (in Cairo-Egypt).

\section{Objectives}

The research aims to set criteria for providing both natural and artificial illumination and colors, together with bases for interior design of different spaces within the living room (in Cairo-Egypt):

1. Determining suitable colors and lighting for different spaces.

2. Effect of light on viewing main surfaces in per- 
spective form of space.

3. Clarifying relationship effect of texture, color and light on the space.

4. Deciding the sources of light and their effect on vision.

5. Illustrating the look of colors and wall surface texture due to type and place of light fall.

\section{The Delimitations:}

The study is limited to the Living Room in Cairo-Egypt. It will focus on matters of colors and lighting and their effective relationship within the interior space. This study adopted an interpretive quantitative data and a descriptive analytical approach.

\section{Methodology:}

This study adopted an interpretive quantitative data and a descriptive analytical approach is implemented through a thorough study of colors and lighting and their effective relationship within the interior space, using nature as a source of inspiration. There is also a presentation, analysis and description of models for interior space design works. This demonstrates the formation idea and proposed implementation criteria to ultimately reach the design idea of the inner space. A survey has been made, the results of the questionnaire that was presented to specialized and non-specialized people of our field.

The research sample includes the development of a hypothetical selection of the sample to include (28) specialized interior architecture designers who acquired experiences of not less than (15) years and (22) non-specialized highly qualified males and females from different fields, their age ranges from 30 to over 40 years. The program ran for duration of one week.

\section{3-1 Study Sample \& Questionnaire:}

The following is an analytical case study where different groups of colors and different styles of lighting (natural and artificial)are selected for use within the space of living room. To measure the effectiveness of study, we prepared a questionnaire that presented required design bases for selected colors and lighting groups in living rooms (in Cairo-Egypt), aiming to measure the physiological and psychological effect of the selection for colors and lighting on man inside the different spaces and the implementation of the questionnaire results to prove that the general target of the program has occurred.

The research sample includes the development of a hypothetical selection of the sample to include (28) specialized interior architecture designers who acquired experiences of not less than (15) years and (22) non-specialized highly qualified males and females from different fields, their age ranges from 30 to over 40 years. The program ran for duration of one week. The form of the questionnaire focuses on the design process regarding the following:

- Selecting the area of interior spaces (small, medium, large) and its influence on the criteria of choosing the elements of the interior architectural design.

- Emphasizing the importance of using suitable colors and the effect of this on the space and characteristics of colors, psychological and physiological effects.

- Focusing on the relationship between color and the area of interior space.

- Psychological and physiological effect of light on the space.

- Highlighting the effect of light on colors within the space.

- Integrating the types of lighting to achieve good space aesthetically and functionally.

- Integration of color scheme with texture.

- Furniture selection and its role in making the interior design of space a success.

- The role of furniture size, color and texture within the space.

- Illumination and colors as dominating elements for visual interconnection in the space.

- The role of light and colors to create a certain harmony and dominating idea over the design.

- Achieving the elements of creativity and breaking boredom in the space.

- Providing different types of lighting to satisfy main functions within the space.

- Lighting and colors influence to achieve tranquility and comfort in the space.

- The role of space boundaries in forming a dominating vision of the design.

- The role of space boundaries in achieving a good space.

- Emphasizing the importance of natural lighting within the space.

- How to successfully utilize natural lighting in the space.

Answers to the questionnaire are classified regarding the way, the role and the effect of lighting and color change in different areas of the living spaces: 


\begin{tabular}{|c|c|c|c|c|}
\hline 1 & 2 & 3 & 4 & 5 \\
\hline Neither & Strongly disagree & Disagree & Agree & Strongly agree \\
\hline
\end{tabular}

Table (1) sample of questionnaire issues (1, 2, 3, 4 parts) about the role of color and lighting (natural, artificial) affecting the design process of the interior space of living room.

\begin{tabular}{|c|c|c|c|}
\hline \multicolumn{2}{|c|}{ Arch. elements } & Ser. & Issue \\
\hline \multirow{17}{*}{$\frac{\overline{0}}{0}$} & \multirow{6}{*}{$\begin{array}{l}\frac{n}{\bar{\sigma}} \\
\overrightarrow{3}\end{array}$} & 1 & $\begin{array}{l}\text { Effect of dark colors on } \\
\text { space }\end{array}$ \\
\hline & & 2 & $\begin{array}{l}\text { Effect of medium } \\
\text { colors on space }\end{array}$ \\
\hline & & 3 & $\begin{array}{l}\text { Effect of light colors on } \\
\text { space }\end{array}$ \\
\hline & & 4 & $\begin{array}{l}\text { Effect of warm colors } \\
\text { on space }\end{array}$ \\
\hline & & 5 & $\begin{array}{l}\text { Effect of cool colors on } \\
\text { space }\end{array}$ \\
\hline & & 6 & $\begin{array}{l}\text { Effect of colors } \\
\text { supported by patterns } \\
\text { (main, horizontal lines, } \\
\text { ornaments) on space }\end{array}$ \\
\hline & \multirow{6}{*}{$\stackrel{\infty}{:}$} & 7 & $\begin{array}{l}\text { Effect of white color on } \\
\text { space }\end{array}$ \\
\hline & & 8 & $\begin{array}{l}\text { Effect of dark color on } \\
\text { space }\end{array}$ \\
\hline & & 9 & $\begin{array}{l}\text { Effect of medium color } \\
\text { on space }\end{array}$ \\
\hline & & 10 & $\begin{array}{l}\text { Effect of color on } \\
\text { sensation of elevation } \\
\text { in space }\end{array}$ \\
\hline & & 11 & Effect of glossy surface \\
\hline & & 12 & Effect of mat surface \\
\hline & \multirow{5}{*}{$\frac{\grave{0}}{\dot{0}}$} & 13 & Effect of light color \\
\hline & & 14 & Effect of medium color \\
\hline & & 15 & Effect of dark color \\
\hline & & 16 & Effect of glossy surface \\
\hline & & 17 & Effect of mat surface \\
\hline
\end{tabular}

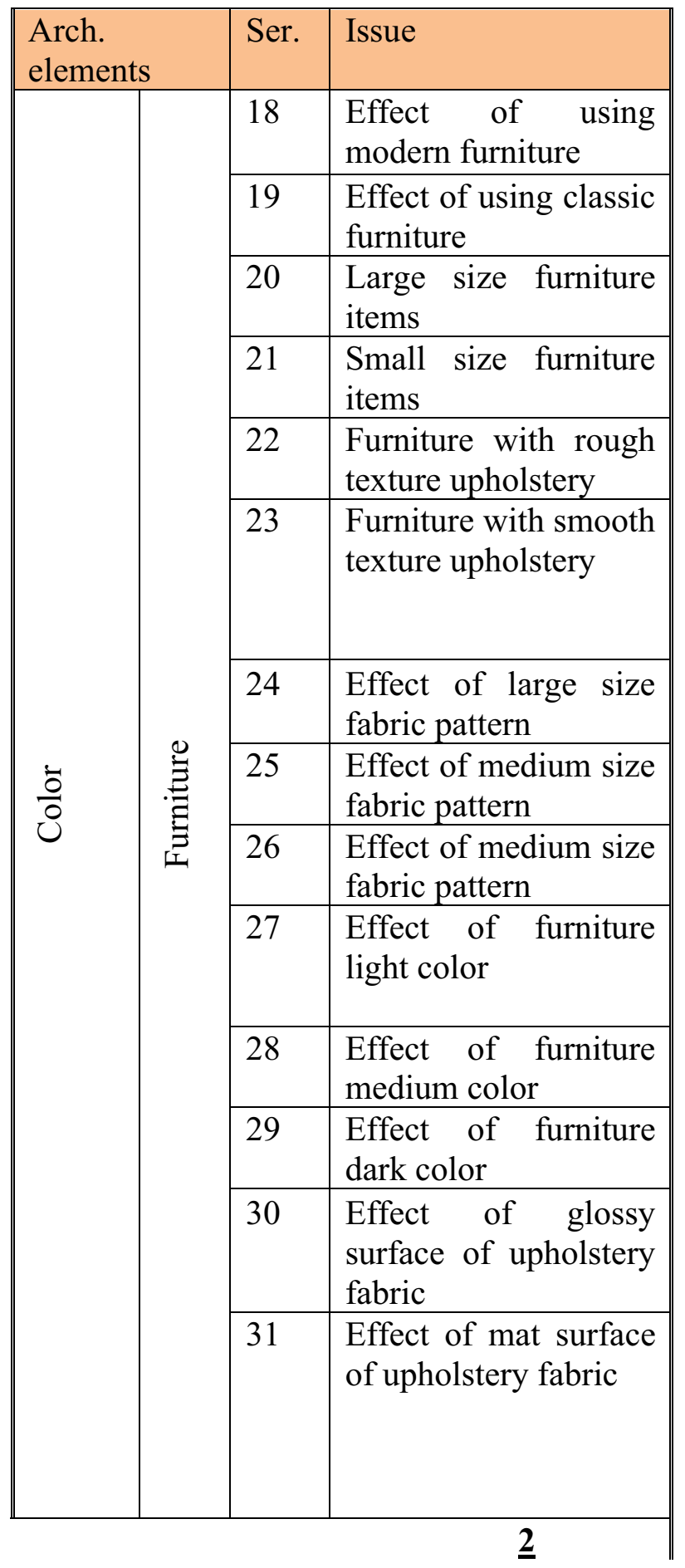




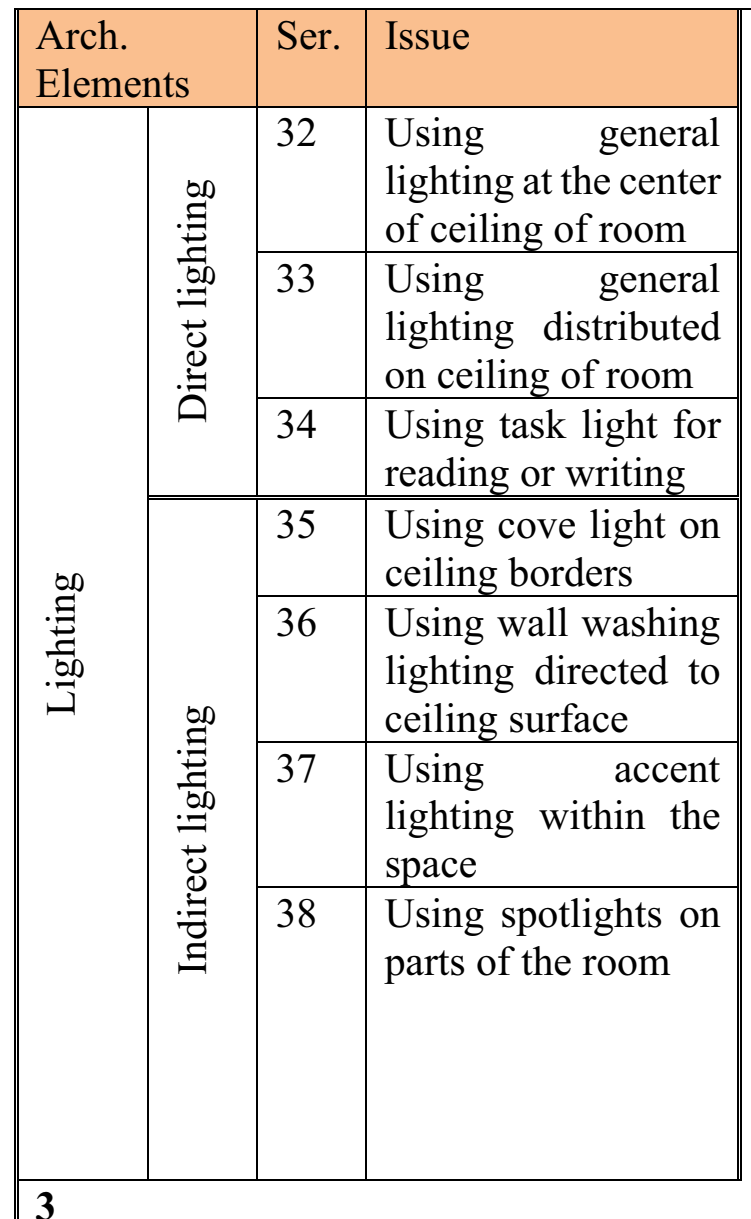

\begin{tabular}{|c|c|c|c|}
\hline \multicolumn{2}{|c|}{$\begin{array}{l}\text { Arch. } \\
\text { elements }\end{array}$} & Ser. & Issue \\
\hline \multirow{9}{*}{ 疱 } & \multirow{9}{*}{ 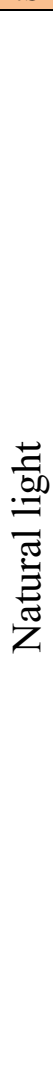 } & 39 & Large-size openings \\
\hline & & 40 & Medium size openings \\
\hline & & 41 & Small-area openings \\
\hline & & 42 & $\begin{array}{l}\text { Effect of multi openings on } \\
\text { the wall }\end{array}$ \\
\hline & & 43 & $\begin{array}{l}\text { Position of opening in the } \\
\text { middle of the wall vertically }\end{array}$ \\
\hline & & 44 & $\begin{array}{l}\text { Position of opening at the } \\
\text { end of wall vertically }\end{array}$ \\
\hline & & 45 & $\begin{array}{l}\text { Opening positioned at the } \\
\text { middle of wall height. }\end{array}$ \\
\hline & & 46 & $\begin{array}{l}\text { Opening positioned at the } \\
\text { end of wall height. }\end{array}$ \\
\hline & & 47 & $\begin{array}{l}\text { Opening positioned at the } \\
\text { corner between two walls }\end{array}$ \\
\hline
\end{tabular}

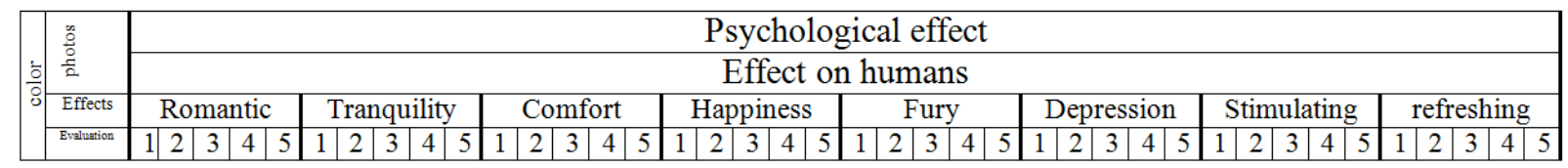

\begin{tabular}{|c|c|c|c|c|c|c|c|c|}
\hline \multirow{3}{*}{\begin{tabular}{|l}
$\frac{2}{8}$ \\
$\frac{2}{20}$ \\
Effects
\end{tabular}} & \multicolumn{8}{|c|}{ Psychological effect } \\
\hline & \multicolumn{3}{|c|}{ Effect on humans } & \multicolumn{5}{|c|}{ Effect on space } \\
\hline & Cool effect & Warm effect & Mobility & $\begin{array}{l}\text { Used as a } \\
\text { basic color }\end{array}$ & $\begin{array}{l}\text { Used as a } \\
\text { secondary } \\
\text { color }\end{array}$ & $\begin{array}{c}\begin{array}{c}\text { Breadth of } \\
\text { space }\end{array} \\
\text {. }\end{array}$ & $\begin{array}{c}\text { Narrowness } \\
\text { of space }\end{array}$ & $\begin{array}{c}\text { Feeling of } \\
\text { mass in } \\
\text { space }\end{array}$ \\
\hline avaluation & \begin{tabular}{l|l|l|l|l}
1 & 2 & 3 & 4 & 5 \\
\end{tabular} & \begin{tabular}{l|l|l|l|l|}
1 & 2 & 3 & 4 & 5 \\
\end{tabular} & \begin{tabular}{l|l|l|l|l}
1 & 2 & 3 & 4 & 5 \\
\end{tabular} & \begin{tabular}{l|l|l|l|l|}
1 & 2 & 3 & 4 & 5 \\
\end{tabular} & \begin{tabular}{l|l|l|l|l|}
1 & 2 & 3 & 4 & 5 \\
\end{tabular} & 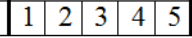 & \begin{tabular}{l|l|l|l|l}
1 & 2 & 3 & 4 & 5 \\
\end{tabular} & \begin{tabular}{l|l|l|l|l}
1 & 2 & 3 & 4 & 5 \\
\end{tabular} \\
\hline
\end{tabular}

Though provoking

12345
Refreshing

12345 

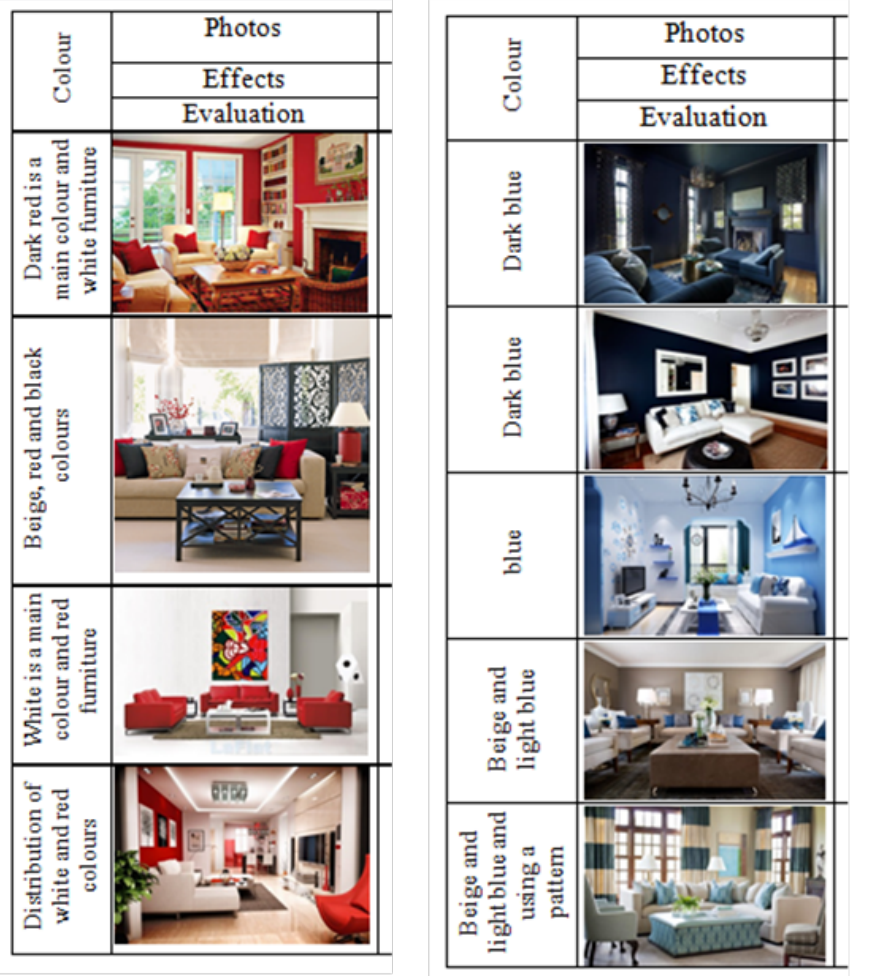

All colors have physiological effect on body muscles and chronic and acute ailments with an emphasis on the following:

- Stressing that white, black and beige are neutral colors.

- Selecting photos depended on:

- Furniture color.

- Color of internal architecture elements.

Fig. (1) sample of the questionnaire issues about the psychological effect of color and lighting (natural-artificial) on humans and space which control the design process and internal space of living room \& Sample of photos where different groups of colors.

From the aforementioned model, the criteria and important points can be established to be clarified in the following analytical plan:

The questionnaire includes an analytical study stressing on two parts: the first is analyzing the selection of suitable colors and the role that colors have inside the space regarding the psychological effect on man and his perception for the space in relation to function and beauty and observing the size and extent of using the color and its degree together with the role of color as a main or secondary factor and determine its interactive effect on individuals (the study sample). The second part concentrates on lighting styles and patterns and their effect and importance to man and the space, together with its direct relationship with color sensation. The questionnaire was individually handled by participants as they were neither allowed to interact with each other nor with the researcher. Table (2), fig. (1)

The space of living room is selected because of its importance and the variation in its functions where general illumination is required. It is preferred to be able to control lighting level in addition to the availability of task lighting for reading and writing as an example. Results of the evaluation and questionnaire indicated the importance of utilizing direct and indirect lighting. The extent of satisfaction and achieving a general atmosphere that commensurate with the multi-function of the living room space. Effect of selecting light colors is investigated together with its contribution in the effectiveness of the lighting design. The possibility of utilizing wall washing is measured as it has a good effect when it reflects from the wall surfaces of the space giving a deceptive visual effect of the height of the ceiling. Lighting has a very significant role because of its effect on colors within the architectural space as different light intensity makes a marked change in the color value. Colored light influences the hue of the wall as the color appears in a different way when receives different color light. On the other hand, color itself has a role on reflected light in the space, light colors increases the reflectivity of light in the space. Warm colors give a feeling of increasing the intensity of used light whether it is natural or artificial light.

Colors have an important role and effect on humans. 
The color has an effect on the person's emotions as they may differ from tranquility to fury or from happiness to depression etc. Colors can affect individual's feelings in different ways some are direct and others are indirect. It depends on the individual himself. (Direct effects appear somehow as general appearance such as joy or grief, lightness or heaviness; we may feel cool or warm, but secondary indirect effects differ according to the individual and they are caused by emotional interrelationship whether subjective or objective automatically generated by the effect of colors). For instance, you feel warm when seeing red, orange or yellow colors. You may feel cool when seeing blue or green colors. Dark colors usually have boring effect and sadness, in contrast to light cheerful and dynamic colors. Psychological effects differ from one color to another. Blues and greens have a calming effect, while the yellow color is cheerful and attracts the attention but in the same time is not recommended for use as a main color in spaces is continually used for prolonged time. Also red color is exciting and dynamic. Fuchsia gives gloomy feelings and is not recommended to large areas. Orange color is a warm stimulating color and can also be considered as an appetizing color when used in certain limited places. colors may also have a weight or density effect on surfaces and masses within the space, light, cool colored surfaces appear to our eyes of less weight than those with warm or dark colors. Fig. $(2,3)$

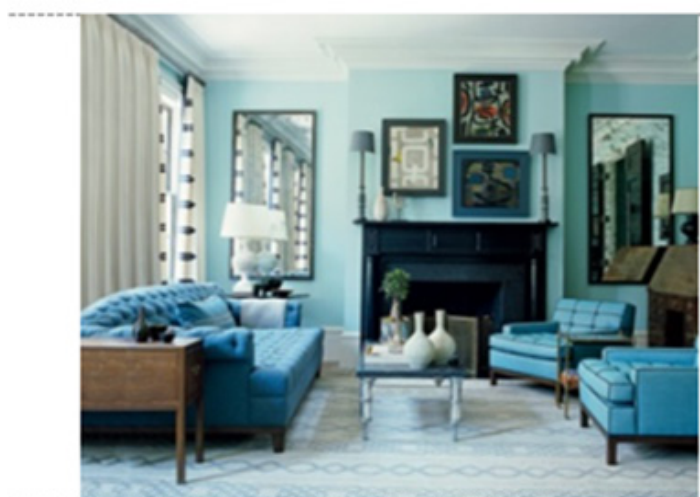

Fig. (3) Using cool colours in the space of living room.

In addition to spatial effect of colors in space, light colors appear as if they bounce out giving a feeling of width for the space while when warm colors they look as if they advance giving the feeling of shortening distances and space constraints.

Evaluation of relationships resulting from colors and lighting usage for spaces may have different effect from one space to another according to the area (small - medium - large). Accordingly, the questionnaire is presented and findings are evaluated to reach design criteria that functionally and aesthetically serve the space according to its specifications.

First: Results of the questionnaire prove that in case of a small area living room: 95 per cent of the questionnaire participants see that using white and light colors as main color and warm cheerful colors e.g. red and green colors as secondary colors make the space look wide and gives its users a feeling of tranquility and comfort.

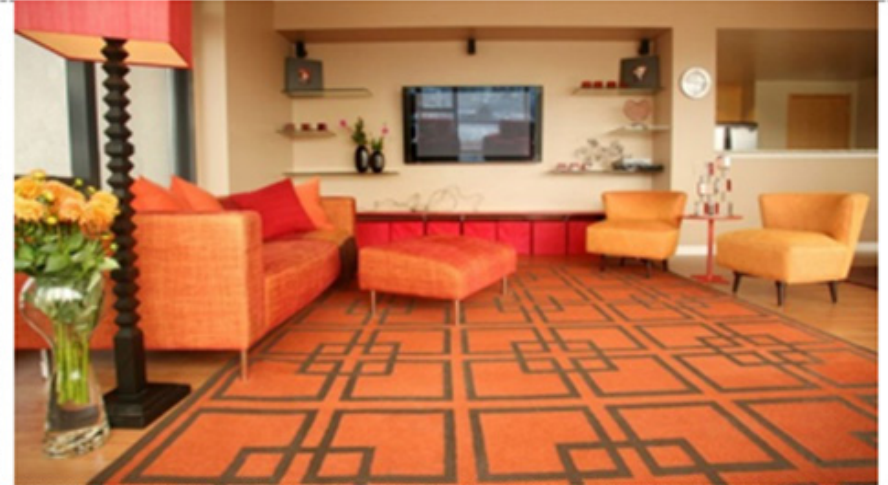

Fig. (2) Using warm colours inside space of living room.

90 per cent of the questionnaire sample confirms the possibility of using light blue as a main color to give a calming effect with lighting and a variety of warm colors as secondary ones. The majority of the sample strongly prefer nature-inspired color schemes emphasizing the utilization of light colors for walls and furniture, together with selecting simple small size furniture units.

99 per cent of the participants saw that white color for ceiling is a necessity because it gives good sense of breadth to the space and strong light reflection. Fig.(4)A,B,C 


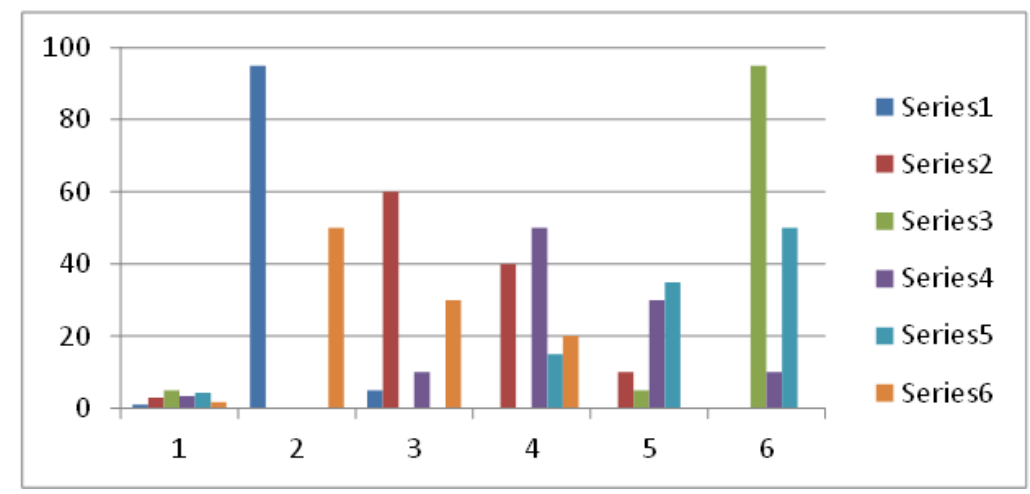

(A)

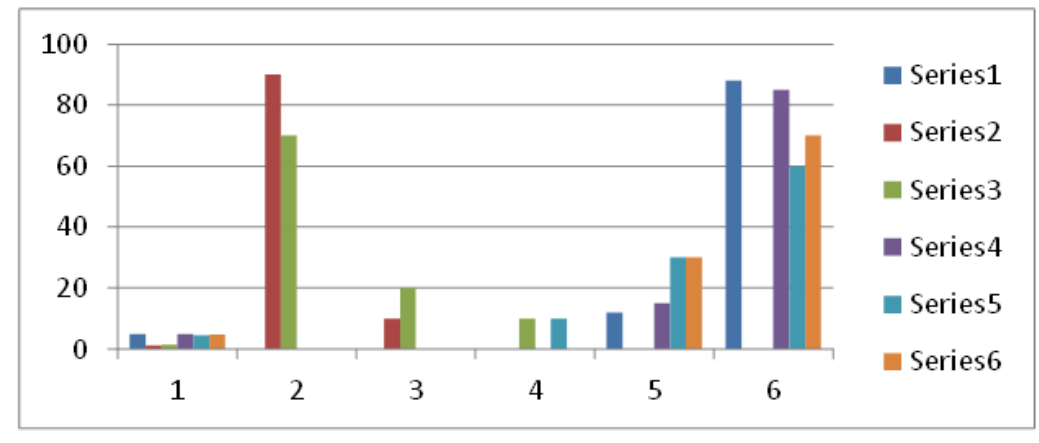

(B)

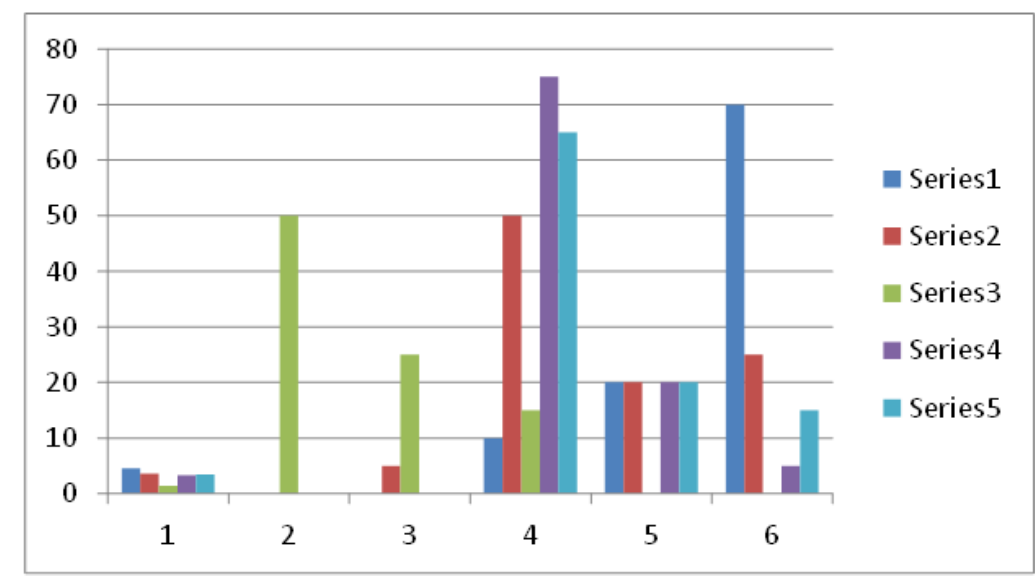

(C)

Fig.(4) (A) Questionnaire preferences of selecting colors for walls of small area living room.

(B) Questionnaire showing that participants prefer choice for ceiling colors in small area living room

(C) Questionnaire show sample preferences for floor colors of small area living room.

Majority of our sample emphasize the use of medium and light colors for floors helps to give feeling of breadth to space particularly if surfaces are bright but with materials of less brightness for furniture. This adds to the warm feeling of the space. Large-size window openings help the penetration of more natural light, giving that sense of breadth. Good care should be given to the po- sition of the windows because if windows are on southern or western walls special inside and outside treatment will be required to avoid the heat and glare problems within the space. Here the space will need some renovation in artificial indirect lighting with no delineation of the space borders. There might be a need for direct task lighting for reading and writing. 


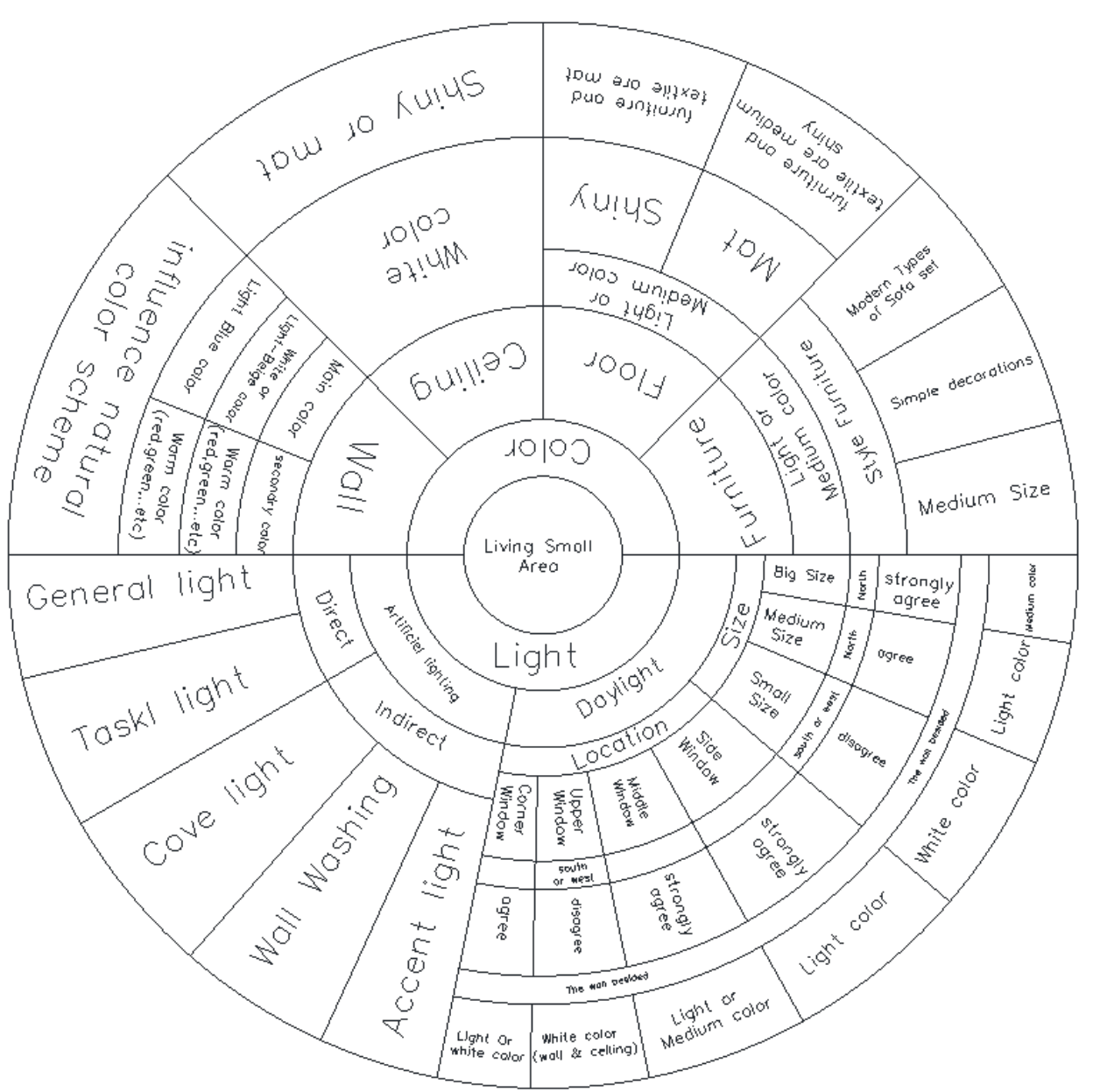

Fig. (5) An analysis showing the interrelations of all architectural design bases and space elements utilizing required design and physical characteristics of light and color for a small area living room.

It is clear that there must be a harmonious relationship among all elements such as furniture colors (giving consideration to size, simplicity and pattern elements) and floors (characteristics of glossy and mat), ceiling (glossy or mat) and wall colors (if main or secondary, if glossy or mat). Also, the relation between illumination whether natural (with deciding about the size of openings - relation with color and if direct or indirect) or artificial (deciding the direction and if direct or indirect with used colors). Fig.(5)

That is detailed explanation of previous plan and its relationship with design criteria of elements of space of small area living room:

\section{Artificial lighting:}

* Required and very useful inside the designed space taking in consideration the geographic position of windows, their position in the wall and their areas.

* If located in a southern or western direction, a spe- cial treatment is called for to avoid glare.

* If located to the north allows for using large opening areas.

* Large windows help to give a feeling of breadth to the space.

\section{Natural lighting:}

* Has to be general lighting.

* Task lights (for reading, writing ...)

* Innovate new methods for using indirect lighting to reflect width of space without delineating the space.

\section{Floors:}

* Using medium and light colors helps to give a feeling of width to space.

* It is preferred to use glossy surfaces but with upholstery materials of less brightness to give the feel of warmth. 
Walls:

* White as a main color and warm cheerful colors as secondary (red - green).

* Light blue can be used as main color to give a calm effect with the warm variation of secondary colors.

* Using color schemes that are inspired by nature is quite successful.

Ceiling:

* White should be used to utilize the positive effect of widening the space and raising the ceiling.

Furniture:

* Medium and small size pieces are preferred.

* Disregard closed furniture.

* Using furniture of light color schemes and warm secondary colors.

In case of medium size living room:

Study confirms the idea of using medium color in one wall only in the space of medium size areas or using it in timber colors and accessories when added to the space. Light and medium colors are used within the space in a balanced way. Ornamental patterns can be used in the space. It is also possible to use furniture with simple ornaments and decorations. Medium size furniture pieces are recommended. These ideas are adopted by 90 per cent of survey sample.

- $\quad 95$ per cent prefer to use white or light colors ceiling to avoid negative effect on the room width.

- Number of participants is equally divided between those who select medium colors and those who go for light colors for floors. A percentage of 30 per cent select medium-size opening for the space and 70 $\%$ opt for large-size openings because they help to allow good natural light into the space taking in consideration avoiding direct falling on the T.V. set. The space need diversity in using indirect and cove light to give the effect of high ceiling. Fig. (6) A,B,C
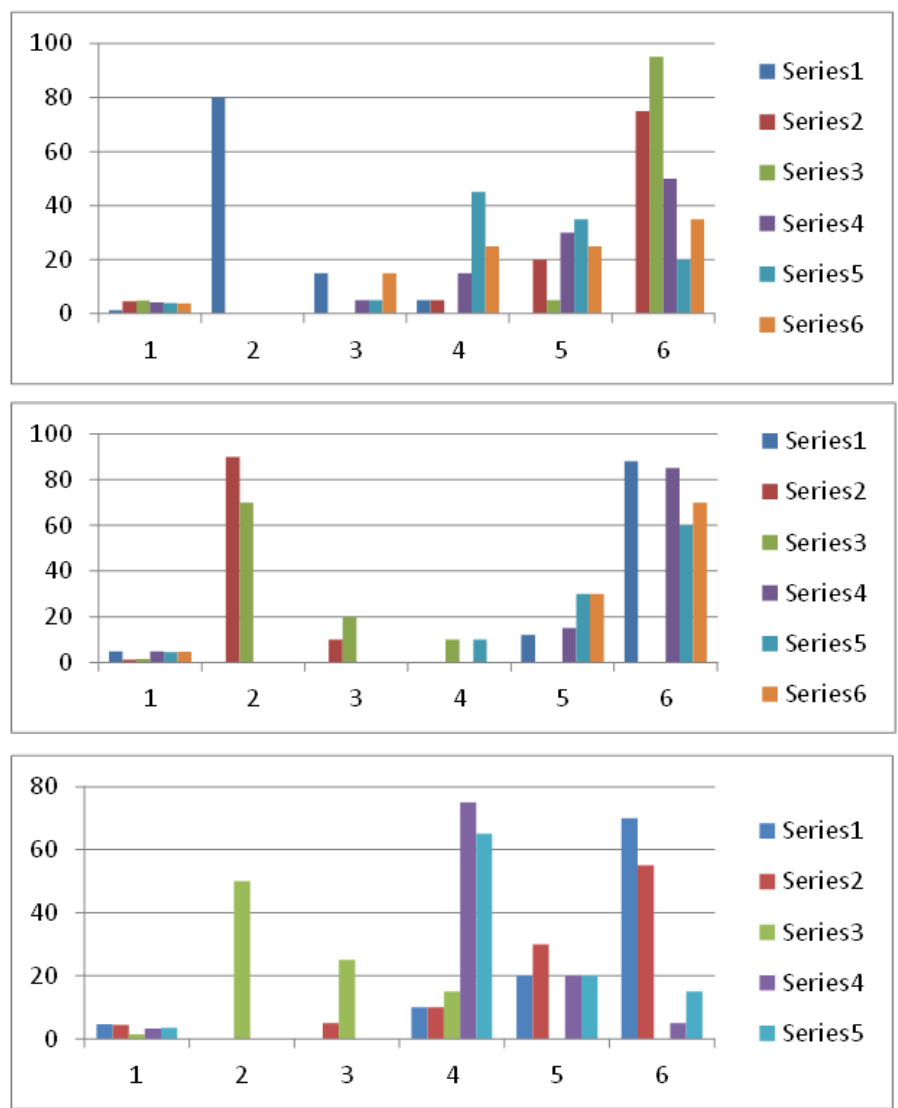

(A)

(B)

(C)

Fig. (6) (A) Questionnaire showing preference of study sample in selecting walls colors in medium size living room

(B) Questionnaire showing preference of study sample to selecting ceiling colors in medium size living room.

(C) Questionnaire showing sample preferences regarding color selection for floors of medium size living room. 


\section{In case of large area living room}

In case of large areas 80per cent of participants prefer dark colors as main colors and light colors as secondary colors for walls and furniture. Diversity in designs and shapes of furniture pieces is favored without any exaggeration which might affect the function and importance of space.

- Regarding ceiling: 90 per cent affirm the pos- sibility of using medium degree colors for ceiling which gives a feeling of familiarity to family member within the space.

-Regarding the floors: 75 per cent of the sample emphasize selecting medium colors for floors if the ceiling is dark, while selecting dark color for the floor in case of white ceiling. Fig. (7) A,B,C
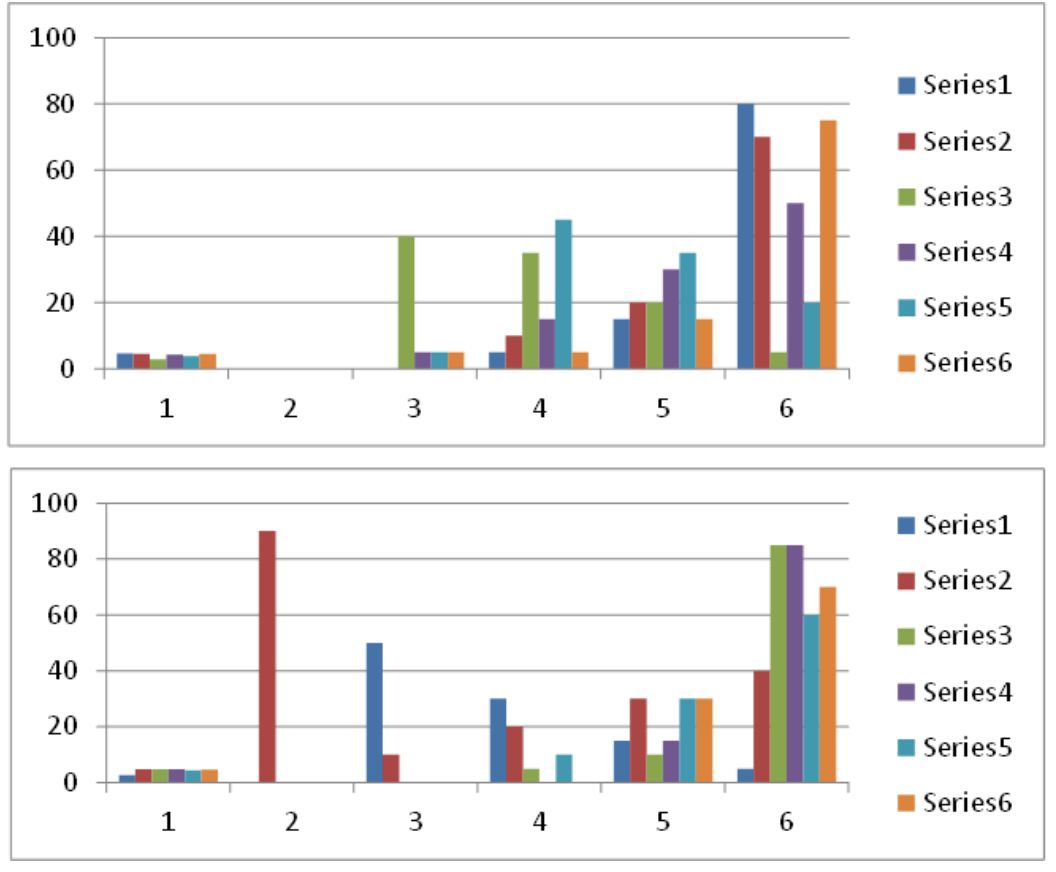

(B)

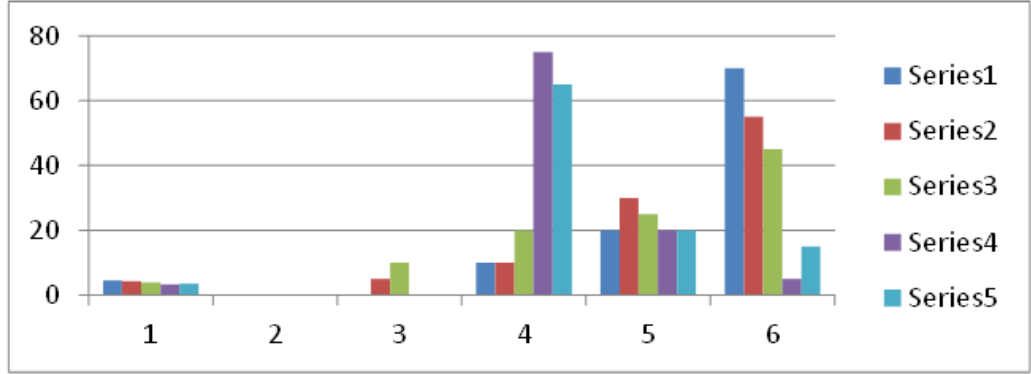

(C)

Fig. (7)(A) Shows preferences in selecting wall colors for large area living room.

(B) The questionnaire showing that study sample preferences for ceiling colors in large area living room

(C) The questionnaire showing that study sample preferences for colors of the floor in large area living room.

The questionnaire emphasizes that space is in need of openings distributed along the larger wall. If openings are on the side, care should be given to the way light is reflected in the space to maintain the sensation of spaciousness and personal calmness inside the architectural space. Results of the questionnaire also indicates that there is some preference to use indirect lighting taking in consideration that too much light may lead to eye strain and may make people feel tense 
in the space.

The following findings are concluded from the questionnaire:

\section{4- Results:}

The research study aims to identify the effects of light and color on the space of the living room, achieving the relationship between them to meet requirements and elements of architectural interior space. The study came to the following conclusions:

1. Focusing on the effect of light on colors within the space is a must.

2. Consideration should be given to the role of light and color as dominating elements of the visual interconnection of space.

3. Supporting the role of light and color to create a certain rhythm and dominating idea for the design.

4. There is an effective influence of light and color in achieving calmness and comfort in the space.

\section{5- Recommendations:}

Through the analytical study and presenting ideas and techniques of employing the functions and characteristics of colors and light in interior architectural space, the research study concludes a number of recommendations that may lead to supporting the effect of light and color in living rooms. Those recommendations are shown as follows:

1. The recommends to concentrate on the role of light and color in realizing the aesthetics of space.

2. The study recommends the permanent confirmation of visual stimulation within the space of living room using light and color as controlling elements.

3. The research confirms the role of the designer of interior architecture in the everlasting search for achieving aesthetics of the space and looking for any renovations in the field of interior design.

4. The study recommends researching and implementing criteria and considerations of color selection in interior design to come up with designs that achieve function and aesthetic values.

5. It is of great importance to acquire a thorough knowledge of the science and theories of colors together with their effect on different psychological functions before going through study of colors of the interior space.

6. The study emphasizes the utilization of the characteristics of colors to enhance the values of warmth or coolness sensation.

7. The study also stresses on highlighting of function and aesthetic aspects of space using light and color.

\section{6- References:}

1. Ander, G. D. (2003). Daylighting performance and design: Wiley.

2. Bartholomew, R. (1975) The luminous environment and human behavior, Journal of Interior Design, Vol. 1, No. 1, pp. 28-39

3. Bellizzi, J. A., Crowley, A. E., and Hasty, R. W. (1983). The effects of color in store design. Journal of Retailing, 59(1), pp.5-8.

4. Boyce, P. R. (2006) Education: the key to the future of lighting practice: the Trotter- Paterson

5. Bynum, C., Epps, H. H. \& Kaya, N. (2006) Color memory of university students: influence of color experience and color characteristic, College Student Journal, Vol. 40, No. 4, pp. 824-31

6. Chiazzari, S. (1998). The Complete Book of Color, Elements Books Ltd., Boston.

7. Crowell, N., Need, A. L. \& Wells, W. V. (1980) Color connotations: a study of color block testing, Journal of Interior Design, Vol. 6, No. 1, pp. 56-9

8. memorial lecture presented to the Society of Light and Lighting, London, February 2006,Lighting Research \& Technology, Vol. 38, No. 4, pp. 28394

9. Daggett, W. R., Cobble, J. E., \& Gertel, S. J. (2008). Color in an Optimum Learning Environment.

10. Durak, A., Olguntürk, N. C., Yener, C., Güvenç, D. \& Gürçınar, Y. (2007). Impact oflighting arrangements and illuminances on different impressions of a room.Building and Environment, 42, pp.3476-3482.

11. Duyan F., Unver R. (2016) : A research on the effect of classroom wall colors on student's attention, ITU AZ, Vol 13, No 2, pp. 73-78.

12. Engelbrecht, K. (2003). The impact of colour on learning. Chicago, IL: Perkins \& Will.

13. Ertek, H. (1994). İç Mekan Temel Tasarım İlkelerine Bir Yaklaşım. Unpublished MA Thesis, Hacettepe University, Ankara.

14. Fielding, R. (2006). Learning, Lighting and Color: Lighting design for schools and universities in the 21st century. 1-7. Retrieved from http:// eric.ed.gov/ERICWebPortal/search/detailmini. 
jsp?_nfpb=true\&_\&ERICExtSearch_SearchValue_0=ED497664\&ERICExtSearch_SearchType $0=$ no\&accno $=$ ED497664

15. Flynn, J. E., Segil, A. W. \& Steffy, G. R. (1988). Architectural interior systems:lighting/ acoustics/ air conditioning (2nd ed.). New York: Van Nostrand Reinhold.

16. Flynn, J. E., Hendrick, C., Spencer, T. J. \& Martyniuk, O. (1979). A guide to methodology procedures for measuring subjective impressions in lighting.Journal of Illuminating Engineering Society, 8, pp.95-110.

17. Flynn, J. E., Spencer, T. J., Martyniuk, O. \& Hendrick, C. (1973). Interim study of procedures for investigating the effect of light on impression and behavior. Journal of Illuminating Engineering Society, 3 (1), pp.87-94.

18. Gregg, D., \& Ander. (2008). Whole building design guide - windows and glazing. Retrieved 1.11, 2011, from http://www.wbdg.org/resources/ windows.php.

19. Guerin, D. A., Park, Y. \& Yang, S. (1995) Development of an instrument to study the meaning of color in interior environments, Journal of Interior Design, Vol. 20, No. 2, pp.31-41

20. Hoffmann, G., Gufler, V., Griesmancher, A., Bartenbach, C., \& Canazei, M. (2008). Essects of variable lighting intensities and colour tempertures on sulphatoxymelatonin and subjective mood in an experimental office workplace. Applied Ergonomic 39(6), pp.719-728.

21. Kats, G. (2008). Lighting and daylighting. Sustainable construction, pp.221.

22. Knez, I., \& Kers, C. (2000). Effects of indoor lighting, gender, and age on mood and cognitive performance. Environment and Behavior, 32(6), 817.

23. Krstić H., Rađelović D. (2013): Color as a powerful tool in interior design. Proceedings Third international science conference Balkan color ,pp. 568-575

24. Liberman, J. (1990). Light, medicine of the future: how we can use it to heal ourselves now: Bear \& Co.

25. Mahnke, F. H., \& Mahnke, R. H. (1947). Color and light in man-made environments New York: John Wiley \& Sons, INC.

26. Morton, J. (1998). Colour voodoo for the Office. Retrieved from Colourcom.com.

27. Oneworkpalce. (1999). Seeing the Difference,
The importance of Quality Lighting in the Workplace. Workplace Issues. Retrieved from http:// www.pdf-finder.com/The-Importance-of-Quality-Lighting-in-the-Workplace.html

28. Ojeda O.R. \& McCowan, J. Colors. (1997)Architecture in detail. Massachusetts: Rockport Publishers.

29. Pile, J. (1997). colour in interior design. NewYork: McGraw-Hill.

30. Sadat Behbahani N.(2011) : Theoretical Review on Color in Interior Space: An Experimental Assessment of Iranian Houses, Eastern Mediterranean University, Gazimağusa, North Cyprus,.

31. Swirnoff L. (1992)Dimensional Color, New York: van Nostrand Reinhold.

32. Swirnoff L. (2005)Untitled Presentation, Proceedings of AIC Colour 05, Granada, Spain.

33. Varley, H. (1988) Colour. London:Marshell Edition Limited.

34. Varland, J. R . ( 1998 ). The color room: A phenomenological approach to color. In W. Benedict\& M. Uddin Colour

35. Hasol, D. (1990). Mimarlık Sözlüğü, Yem Publishing, İstanbul.

36. Heller, E. (2009). Psychologie de la couleur: effets et symboliques, Pyramyd, Paris.

37. Zelanski, P., Fisher, M. P. (2003). Color, Fourth Edition, Prentice Hall Inc. New Jersey. 